\title{
TdT-Mediated dUTP Nick End Labeling
} Assay

National Cancer Institute

\section{Source}

National Cancer Institute. TdT-Mediated dUTP Nick End Labeling Assay. NCI Thesaurus.

Code C19815.

A method to detect apoptosis. 